\title{
Verification Tests of Frictional Heat Modelling Results
}

\author{
Andrzej BORAWSKI*, Dariusz SZPICA**, Grzegorz MIECZKOWSKI**** \\ *Bialystok University of Technology, 45C Wiejska Str., 15-351 Bialystok, Poland, E-mail: a.borawski@pb.edu.pl \\ **Bialystok University of Technology, 45C Wiejska Str., 15-351 Bialystok, Poland, E-mail: d.szpica@pb.edu.pl \\ ***Bialystok University of Technology, 45C Wiejska Str., 15-351 Bialystok, Poland, E-mail: g.mieczkowski@pb.edu.pl \\ cross $^{\text {ref }}$ http://dx.doi.org/10.5755/j01.mech.26.3.23775
}

\section{Introduction}

Friction is one of the most common phenomena in nature. Without it our lives would be completely different, as many seemingly ordinary things would cease to exist, like, for instance, thread connections [1,2]. Friction is also related to many other phenomena, the most popular being heat and wear [3]. Unfortunately, measuring these effects may be difficult, if not impossible [4]. That is why many researchers determine such parameters using simulations. While there are numerous methods of conducting simulations, tribology usually depends on computer-based simulations [5]. The most significant benefit of using this method is its cost effectiveness. Additionally, it produces fast results, and the test framework may be adjusted at will, because it is free from equipment limitations which occur in real-life experiments. Conducting simulations requires only a computer with suitable software [6]. The finite element method is commonly used in research. It is frequently utilised to study temperature in friction pairs [7]. Additionally, it may be employed to simulate wear, contact pressure, deformation or stress [8-11].

Of course, the above method has some limitations. One of the main drawbacks is the need for thorough knowledge of the studied phenomenon, and its mathematical description [12]. If imprecise mathematical models are used, the results may come with significant errors. Unfortunately, some phenomena are very difficult to describe with the help of math equations (e.g. the impact of wear process products or dust coating of friction surfaces on tribological parameters). That is why it is worthwhile to test the results in a verification study. It helps to determine the differences between the results of real-life experiment and those obtained in simulation tests $[13,14]$. Many scientists do this using existing laboratory stations. In such cases, a computer model of the studied combination is created, and thanks to a good recreation of real-life conditions, the simulation results may be verified with high accuracy. Perez et al. determined the theoretical value of the friction force between two cooperating surfaces. Then they used the pin-on-disc test stand to validate the obtained results [15]. Abdullah and Achlattmann attempted to determine the temperature distribution on the friction surface [14]. The obtained results were also verified in laboratory conditions by using linear cooperation geometry. Hegadekatte et al. dealt with similar subjects [16]. However, they looked at wear in a slightly different way. They analyzed the cross section of the friction path. Yan et al. also dealt with wear phenomena. Their approach was different from that of other researchers because they used a ball and disc as friction pairs [17]. They also validated the results using a laboratory stand. Bortoleto et al. presented the results of the simulation, which includes formation of oxides and wear products [18]. Verification of theoretical results shows a high correlation coefficient. Shipway and Masen et al. also simulated the wear of material in the friction process and verified the results obtained using a laboratory stand $[19,20]$. In their case, however, it was a stand with point contact geometry - ball cratering. In literature, validated results of simulation tests of wear with grease can also be found. Such attempt was made by Martini et al. [21].

After analysing numerous publications on the subject, the decision was made to verify how well virtual studies reflect real life conditions. This need resulted mainly from the fact that we have previously conducted simulations of friction pairs (e.g. [22]), but these tests were not compared against empirical experiments. It was therefore decided to use an existing tribotester, develop a mathematical model of its contact pair, and then conduct simulations and empirical tests with identical boundary conditions. Finally, we compared the results obtained using these two methods. As the simulations required data developed empirically, the empirical experiment was conducted first.

\section{Station used to verify the results of simulations}

The results of simulations were verified in a test station owned by the Faculty of Mechanical Engineering at the Bialystok Technical University (Fig. 1). The station comprises in: T-11 tribological tester, MT886 hygrometer, and a Velleman DEM106 temperature sensor with a type K thermocouple.

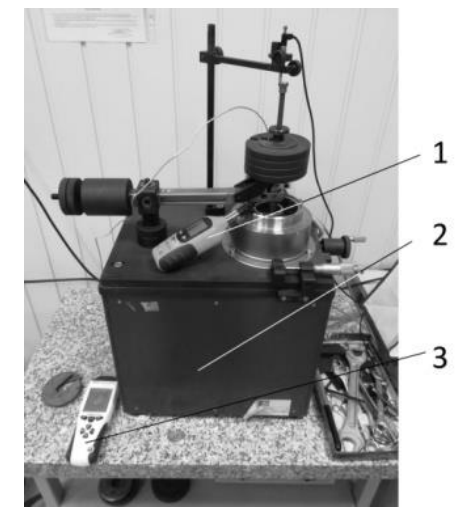

Fig. 1 Station used to verify the results of simulation tests: 1- MT886 hygrometer, 2-T-11 tribological tester, 3- Velleman DEM106 temperature sensor with a type $\mathrm{K}$ thermocouple

The sample used in the experiment is a $1 "$ cylinder made of $27 \mathrm{MnCrB}_{5}-2$ steel. The counter sample was also a 
cylinder, with a $6 \mathrm{~mm}$ diameter and made of Zl250 cast iron. Inside the counter sample a hole was drilled for the thermocouple. The depth of the hole was adjusted to leave $1 \mathrm{~mm}$ of material between the friction surface and the temperature sensor. The basic parameters of the two friction materials are listed in Table 1.

Table 1

List of prepared samples

\begin{tabular}{|c|c|c|}
\cline { 2 - 3 } \multicolumn{1}{c|}{} & Sample & Counter sample \\
\hline Thermal conductivity & $58 \mathrm{~W} /(\mathrm{m} * \mathrm{~K})$ & $47 \mathrm{~W} /(\mathrm{m} * \mathrm{~K})$ \\
\hline Density & $7860 \mathrm{~kg} / \mathrm{m}^{3}$ & $7870 \mathrm{~kg} / \mathrm{m}^{3}$ \\
\hline $\begin{array}{c}\text { Heat capacity at con- } \\
\text { stant pressure }\end{array}$ & $450 \mathrm{~J} /(\mathrm{kg} * \mathrm{~K})$ & $498 \mathrm{~J} /(\mathrm{kg} * \mathrm{~K})$ \\
\hline
\end{tabular}

In order to obtain easily recordable, significant changes in temperature, the following boundary conditions were used: load: $m=5 \mathrm{~kg}$, friction linear velocity $v=1 \mathrm{~m} / \mathrm{s}$, friction path $L=1000 \mathrm{~m}$. The experiment was conducted at $35 \%$ air humidity and ambient temperature of $22^{\circ} \mathrm{C}$. The sample and counter sample had the same temperature at the beginning of the test. As it is impossible to measure the temperature of the friction pair, the measurements were taken from the hole drilled inside the pin. The exact measurement point was approximately $1 \mathrm{~mm}$ from the contact surface. The measurements were taken every $1 \mathrm{~s}$. The experiment made it possible to determine the coefficient of friction between the two materials $(\mu=0,18)$, as well as the abrasive wear rate $\left(K_{c}=1,9347 \cdot 10^{-18} \mathrm{~m}^{3} \mathrm{~N}^{-1} \mathrm{~m}^{-1}\right)$.

\section{Pin-on-disc contact mathematical model}

It should be noted that the considered laboratory station ensures constant sliding velocity and constant contact pressure. The tests performed so far have shown that both the sample and the counter-sample do not heat up to high temperatures. Therefore, some simplifying assumptions were made: the friction coefficient and pressure are constant, and there is contact along the entire surface of the pin.

The simplest way to describe the force of friction between two elements is by using the Amontons-Coulomb law [17]:

$$
F=\mu \cdot N=\mu \cdot m \cdot g,
$$

where: $F$ is friction force, $\mu$ is coefficient of friction, $N$ is normal force, $m$ is pressing mass, $g$ is gravitational acceleration, or using a formula that takes into consideration the adhesion in the friction pair [23]:

$$
F=\tau \cdot A,
$$

where: $A$ is contact surface area (Fig. 1), $\tau$ is shear stress. Knowing the normal force and the actual area of contact, the contact pressure $P_{c}$ can be calculated, which is [24]:

$$
P_{c}=\frac{N}{A}=\frac{F^{2}}{\mu \cdot \tau} .
$$

The work $W$ done in the friction pair can be calculated when the friction force and path are known. Taking into account the duration of the experiment, the power of the friction pair $P_{w r}$ can also be calculated [25]:

$$
P_{w r}=\frac{d W}{d t}=\frac{d}{d t}(F \cdot L)=F \frac{d L}{d t}=F \cdot v
$$

where: $L$ is friction path, $v$ is linear velocity in the friction pair: $v=\omega(t) \cdot R$, where: $\omega(t)$ - angular velocity of the disc, $R$ is average contact diameter of the sample and counter sample. Assuming that friction force occurs only through the contact between the disc and pin, the heat flux $q(R, t)$ may be designated using the equation [7]:

$$
q(R, t)=P_{c} \cdot v(R, t) .
$$

The heat transfer between the sample and counter sample can be expressed as [26]:

$$
\rho \cdot C_{p} \frac{\partial T}{\partial t}+\nabla \cdot(-k \cdot \nabla T)=Q-\rho \cdot C_{p} \cdot u \cdot \nabla T,
$$

where: $k$ is thermal conductivity, $C_{p}$ is thermal capacity, $u$ is heat flux rate, $Q$ is heating power per density unit, $\rho$ is density, $T$ is temperature. Throughout the experiment, the following amount of heat was released through convection and radiation [27]:

$$
q_{d}=-h\left(T-T_{r}\right)-\varepsilon \sigma\left(T^{4}-T_{r}^{4}\right),
$$

where: $h$ is convection coefficient, $T-T_{r}$ is temperature different between the friction material and ambient temperature, $\varepsilon$ is emissivity of the material, $\sigma$ is Stefan-Boltzmann constant. The relation between the convention coefficient and the friction velocity is described as follows [26]:

$$
h=\frac{0,037 k}{R}\left(\frac{\rho \cdot R \cdot v}{\mu}\right)^{0,8} \cdot\left(\frac{C_{p} \cdot \mu}{k}\right)^{0,33} .
$$

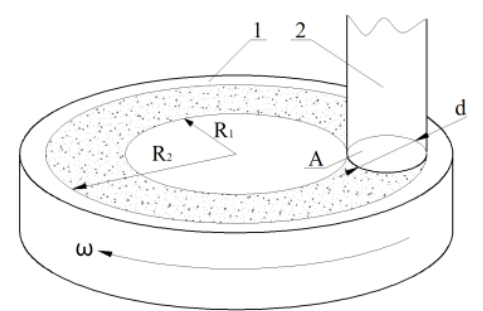

Fig. 2 Sample 1 and counter sample 2 contact diagram: $d$ is counter sample diameter, $R_{1}$ is internal boundary of the friction trail, $R_{2}$ is external boundary of the friction trail, $A$ is contact area

Analysis of the geometry of the sample's and counter sample's contact (Fig. 2), an equation can be created to calculate the area of the friction trail:

$$
S=\int_{R_{1}}^{R_{2}} 2 \pi R(d R)=\pi\left(R_{2}^{2}-R_{1}^{2}\right)
$$

Assuming that the material from which the sample is made of is homogeneous and that wear is evenly distributed, the volume of the debris can be calculated from a simple relation: 


$$
V=S \cdot z=\pi \cdot z\left(R_{2}^{2}-R_{1}^{2}\right),
$$

where: $\mathrm{z}$ is depth of the friction trail created during contact. If the abrasive wear rate coefficient is known $K_{c}$, then this value can be calculated using a transformation of the Archard's equation [28]:

$$
K_{c}=\frac{L \cdot N}{V} \rightarrow V=\frac{L \cdot N}{K_{c}} .
$$

Taking into consideration the density of the studied material, the mass of the sample's debris can be calculated as well $m_{s}$ :

$$
m_{s}=V \cdot \rho \rightarrow m_{s}=\frac{L \cdot N \cdot \rho}{K_{c}} .
$$
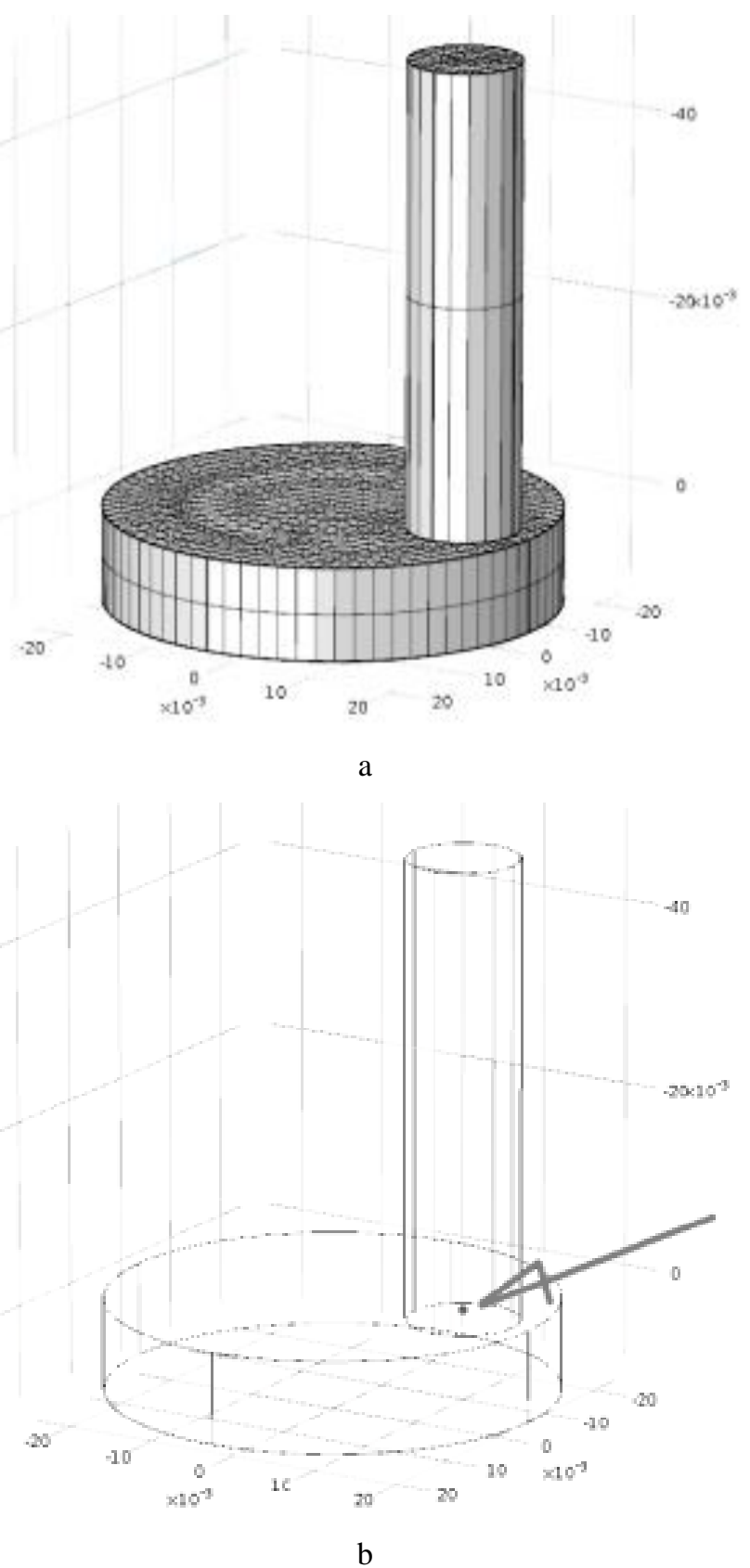

Fig. 3 Pin-on-disc contact CAD model: a) mesh; b) temperature measurement point
Using the equations described above and COMSOL Multiphysics modelling software, a virtual model of the sample and counter sample was made, and a simulation of the friction pair was conducted.

The geometry of the friction elements as well as the boundary conditions were identical to the ones used in the empirical study. A mesh composed of 2844 elements was laid on the friction pair (Fig. 3, a). This gave a total of 14710 degrees of freedom (plus 6924 internal DOFs). Temperature readings, similarly to the empirical experiment, were taken from inside the pin, along its axis and approximately $1 \mathrm{~mm}$ from the contact surface (Fig. 3, b).

\section{Results}

The two test methods produced respective temperature profiles. The graphic form of the results is presented in Fig. 4.

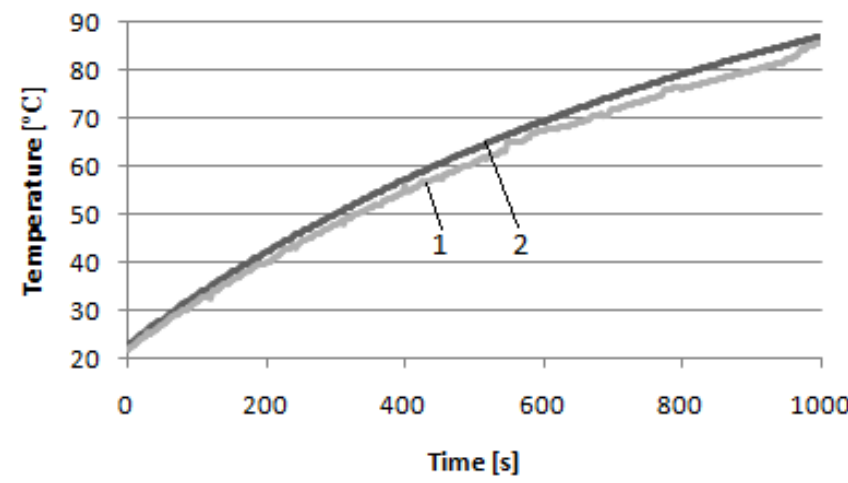

Fig. 4 Temperature measurement results: 1 - empirical tests, 2 - simulations

Goodness of fit of the model to the experiment was evaluated by the coefficient of determination, described as:

$$
R^{2}=\frac{\sum_{i=1}^{n}\left(y_{s}-\bar{y}\right)^{2}}{\sum_{i=1}^{n}\left(y_{e}-\bar{y}\right)^{2}},
$$

where: $y_{s}$ is theoretical value of the dependent variable over time $t$ (calculated in the model), $\bar{y}$ is arithmetic mean of the empirical values of the dependent variable, $y_{e}$ is actual values of the variable over time $t$. After substituting in the formula, $R^{2}=0,93$.

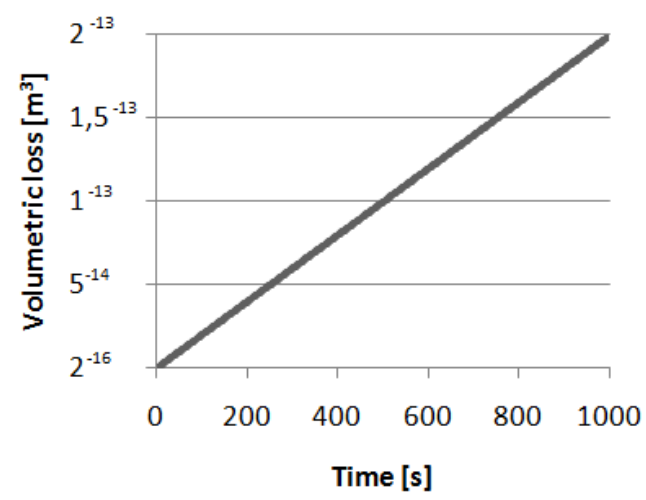

Fig. 5 Loss in volume of the studied sample over time 
The abrasive wear of the sample was also analysed. The empirical experiment showed a mass loss of $1.56 \cdot 10^{-5} \mathrm{~kg}$. As this value was used to calculate the coefficient of abrasive wear rate, which in turn was used in the simulation tests, the results of the simulation turned out identical to the one obtained in the tribotester. The simulation also made it possible to determine the increase of wear over time (Fig. 5), which is impossible in empirical experiments.

\section{Conclusions}

The article describes the empirical tests and simulations of friction between two elements: a disc and pin. The study was conducted using a disc made of $27 \mathrm{MnCrB}_{5}-2$ steel and a pin made of $\mathrm{Zl} 250$ cast iron. The results produced by the two methods were then compared. The following conclusions can be made:

- the results of temperature tests obtained empirically and in simulations are very similar $\left(R^{2}=0,93\right)$, which suggests that computer programmes can be a good tool for solving friction issues;

- in order to conduct a simulation properly, it is necessary to determine selected factors empirically (in this case: density, thermal conductivity, thermal capacity, coefficient of friction and abrasive wear rate);

- the developed model can be used for calculating temperature in places where empirical measurements are impossible (for example, in a friction pair);

- the model makes it possible to monitor real-time material wear, which is significant in studying typical abrasive materials, such as brake linings. However, because this is a different friction pair (with much higher sliding velocity, greater maximum temperatures and larger contact surface), the model should be expanded with equations taking into account: 1 ) variation of $\mathrm{COF}$ and $K_{c}$ values with temperature, 2) actual contact area (which is $15-20 \%$ of the brake pad total surface [29]) and its microgeometry.

\section{Acknowledgements}

The research has been financed from the project no. MB/WM/4/2017, financed from funds used for the development of young scientists and doctoral students, and through the program of the Minister of Science and Higher Education of Poland named "Regional Initiative of Excellence" in 2019 - 2022 project number 011/RID/2018/19 amount of financing 12,000,000 PLN.

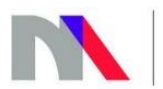

Ministry of Science

and Higher Education

Republic of Poland

\section{References}

1. Nassar, S.; El-Khiamy, H.; Barber, G.; Zou, Q.; Sun, T.S. 2005. An experimental study of bearing and thread friction in fasteners, Journal of Tribology 127(2): 263272.

https://doi.org/10.1115/1.1843167.

2. Hsu, S.; Ying, C.; Zhao, F. 2014. The nature of friction: A critical assessment, Friction 2(1): 1-26. https://doi.org/10.1007/s40544-013-0033-z.
3. Lukaszewicz, A. 2019. Nonlinear numerical model of friction heating during rotary friction welding, Journal of Friction and Wear 39(6): 476-482. https://doi.org/10.3103/S1068366618060089.

4. Diliunas, S.; Leišis, V.; Zeleniakienè, D. 2007. Investigation of stress homogenization near inner cavity in the polymer structure, Indian Journal of Engineering and Materials Sciences 14(6): 408-413.

5. Borawski, A. 2019. Common methods in analysing the tribological properties of brake pads and discs - review, Acta Mechanica et Automatica 13(3): 221-226.

6. Mieczkowski, G. 2018. Optimization and prediction of durability and utility features of three-layer piezoelectric transducers, Mechanika 24(3): 335-342. https://doi.org/10.5755/j01.mech.24.3.17953.

7. Talati, F.; Jalalifar, S. 2009. Analysis of heat conduction in a disk brake system, Heat Mass Transfer 45: 1047-1059. http://dx.doi.org/10.1007/s00231-009-0476-y.

8. Česnavičius, R.; Kilikevičius, S.; Krasauskas, P.; Dundulis, R.; Olišauskas, H. 2016. Research of the friction stir welding process of aluminium alloys, Mechanika 22(4): 291-296. http://dx.doi.org/10.5755/j01.mech.22.4.16167.

9. Adamowicz, A. 2016. Thermal stressed state of a disk in the process of multiple braking, Materials Science 51(6): 814-820. https://doi.org/10.15632/jtam-pl.54.1.205.

10. Dundulis, R.; Krasauskas, P.; Kilikevičius, S. 2012. Modelling and simulation of strength and damping of the support pillar welded by longitudinal weld, Mechanika 18(2): 135-140. https://doi.org/10.5755/j01.mech.18.2.1575.

11. Yevtushenko, A. A.; Kuciej, M.; Grzes, P.; Wasilewski, P. 2017. Temperature in the railway disc brake at a repetetive short-term mode of braking, International Communications in Heat and Mass Transfer 84: 102109.

https://doi.org/10.1016/j.icheatmasstransfer.2017.04.007.

12. Kamiński, Z. 2017. A simplified lumped parameter model for pneumatic tubes, Mathematical and Computer Modelling of Dynamical Systems 23(5): 523-535. https://doi.org/10.1080/13873954.2017.1280512.

13. Khot, S.; Borah, U. 2015. Finite element analysis of pin-on-disc tribology test, International Journal of Science and Research 4(4): 1475-1480.

14. Abdullah, O. I.; Schlattmann, J. 2016. Temperature analysis of a pin-on-disc tribology test using experimental and numerical approaches, Friction 4(2): 135143. https://doi.org/10.1007/s40544-016-0110-1.

15. Pérez, A. T.; Fatjó, G. G.; Hadfield, M.; Austen, S. 2011. A model of friction for a pin-on-disc configuration with imposed pin rotation, Mechanism and Machine Theory 46: 1755-1772. https://doi.org/10.1016/j.mechmachtheory.2011.06.002.

16. Hegadekatte, V.; Huber, N.; Kraft, O. 2006. Modeling and simulation of wear in a pin on disc tribometer, Tribology Letters 24(1): 51-60. https://doi.org/10.1115/IJTC2006-12063. 
17. Yan, W.; O’Dowd, N. P.; Busso, E. P. 2002. Numerical study of sliding wear caused by a loaded pin on a rotating disc, Journal of the Mechanics and Physics of Solids 50: $449-470$. https://doi.org/10.1016/S0022-5096(01)00093-X.

18. Bortoleto, E. M.; Rovani, A. C.; Seriacopi, V.; Profito, F. J.; Zachariadis, D. C.; Machado, I. F.; Sinatora, A.; Souza, R. M. 2013. Experimental and numerical analysis of dry contact in the pin on disc test, Wear 301(1-2): 19-26. https://doi.org/10.1016/j.wear.2012.12.005.

19. Shipway, H. 2004. A mechanical model for particle motion in the micro-scale abrasion wear test, Wear 257: 984-991. https://doi.org/10.1016/j.wear.2004.06.001.

20. Masen, M. A.; de Rooij, M. B.; Schipper, D. J. 2005. Micro-contact based modelling of abrasive wear, Wear 258: 339-348. https://doi.org/10.1016/j.wear.2004.09.009.

21. Martini, A.; Wang, W.; Hu, Y.; Lisowsky, B., Wang, Q. 2007. Simulation of Sliding Wear in Mixed Lubrication, Journal of Tribology 129(3): 453-460. https://doi.org/10.1115/1.2736439.

22. Borawski, A. 2018. Simulation study of the process of friction in the working elements of a car braking system at different degrees of wear, Acta Mechanica et Automatica 12(3): 221-226. https://doi.org/10.2478/ama-2018-0034.

23. Szpica, D. 2018. Modeling of the operation of a Dual Mass Flywheel (DMF) for different engine-related distortions, Mathematical and Computer Modelling of Dynamical Systems 24(6): 643-660. https://doi.org/10.1080/13873954.2018.1521839.

24. Mieczkowski, G. 2019. Criterion for crack initiation from notch located at the interface of bi-material structure, Eksploatacja i Niezawodność - Maintenance and Reliability 21(2): 301-310. http://dx.doi.org/10.17531/ein.2019.2.15.

25. Szpica, D. 2015. Characteristics of motion reserve of passenger vehicle engines, Transport Means 2015: Proceedings of the 19th International Scientific Conference: Dedicated to 25th anniversary of Klaipeda University 1: 9-12.
26. Richardson, J.M.; Coulson, J.F. 1999. Chemical Engineering Vol. 1: Fluid Flow, Heat Transfer and Mass Transfer, The Bath Press, Bath.

27. Carey, V. P.; Chen, G.; Grigoropoulos, C. 2008. A Review of Heat Transfer Physics, Nanoscale and Microscale Thermophysical Engineering 12(1): 1-60. https://doi.org/10.1080/15567260801917520.

28. Yevtushenko A. A.; Grzes P. 2015. 3D FE model of frictional heating and wear with a mutual influence of the sliding velocity and temperature in a disc brake, International Communications in Heat and Mass Transfer 62: 37-44. https://doi.org/10.1016/j.icheatmasstransfer.2015.01.005.

29. Eriksson, M.; Bergman, F.; Jacobson, S. 2002. On the nature of tribological contact in automotive brakes, Wear 252: 26-36. http://dx.doi.org/10.1016/S0043-1648(01)00849-3.

\section{A. Borawski, D. Szpica, G. Mieczkowski VERIFICATION TESTS OF FRICTIONAL HEAT
MODELLING RESULTS}

S u m m a r y

Simulation tests have currently become very popular. It gives access to values and parameters which are difficult or impossible to obtain in real conditions. However, in many cases the accuracy of the results may raise concerns, as not every researcher conducts verification tests. This article looks into the quality of results obtained in virtual tests. The tests were conducted using a pin-on-disc station. The main parameter of the verification study was the temperature of the pin measured along its axis at $1 \mathrm{~mm}$ from the friction surface. This shows that computer models produce results which accurately reflect real-life phenomena.

Keywords: mechanical engineering, brake pads, friction, modelling verification, pin-on-disc.

Received July 05, 2019 Accepted June02, 2020 